\title{
Preface: ordinary cities - place, space, time and biographical narratives
}

Books have many origins. This book has three origins. First, all editors have experience of visiting, researching and even living in smaller towns and cities. These include places like De Smet, South Dakota; Alliance, Nebraska; Molde, Norway; Lichfield, Staffordshire (UK); Crowland, Lincolnshire (UK); or any of the many Malverns - Great Malvern, Little Malvern, Malvern Wells, North Malvern, Malvern Link, West Malvern, Worcestershire (UK). Second, there is a developing literature on smaller towns and cities. The debate on ordinary cities can be traced back to Jennifer Robinson's 2006 book that critiqued the exclusionary nature of much urban theory. Robinson identified a dichotomy in the literature between the emphasis placed on innovative 'global cities' and supposedly more imitative cities in the Global South.

Third, during a visit to New Orleans in 2018 the editors engaged in a broader discussion framed around exploring the dynamics and evolving global geographies of manufacturing. A fascinating discussion developed around the overemphasis in urban theory on more exceptional or extraordinary cities and towns. It was this discussion that led to a conversation to explore the possibilities of an edited book on ordinary cities. This discussion continued over dinner during a visit to Washington, DC in 2019, and a book proposal was developed and submitted to Edward Elgar. These discussions explored the possibilities of persuading urban theorists, and those involved in shaping the conceptual direction of economic geography, to develop a more inclusive approach to theory development. Such an approach would remove the dichotomy identified by Robinson between a geography that was too reliant upon theory developed to reflect the experience of more advantaged places and the need to develop an inclusive rather than an exclusionary approach to understanding the interrelationships between place, space, time, people, and things.

One of the difficulties in developing an edited book under the title Ordinary Cities, Extraordinary Geographies: People, Place and Space is in differentiating between the 'ordinary' versus the 'extraordinary'. These are relative and context-dependent terms. Thus, to one person what is perhaps ordinary is to another extraordinary. The ordinary is about the everyday, the routine, the habitual, and the taken for granted. Nevertheless, extraordinary cities are saturated with ordinary experiences, lifestyles, and processes, while more ordinary 
places also have extraordinary or perhaps unusual aspects. The key issue is to consider places that have been overlooked by social scientists. This is to accept that there are places which are well documented and analysed and other places which are completely ignored. It might mean that these overlooked places are unimportant or that they have been overlooked given some of the constraints placed upon academics in the selection of their objects of study. Journal editors are perhaps more willing to publish papers on well-known places that will be known by an international readership. It might be easier to publish a paper on Palo Alto compared to Redlands, California. Redlands, however, is home to Esri, an international business specializing in the support of geographic information software. This company was founded in Redlands because this was where the founders had grown up and met at high school.

A focus on ordinary towns and cities, or smaller towns and cities, raises questions regarding the development of a more balanced approach to social science research that is focused on place-based processes. Thus, is the social science approach to place currently unbalanced? If it is unbalanced, what form does this imbalance take? Is it possible to develop a more balanced approach and how would this be characterized? What are the drivers or pressures that result in some places being included within social science debates and other places being excluded? It would be difficult to react against the statement that social science should adopt a more inclusive research agenda in which inclusion is defined around research that embraces and engages with a diversity of places.

The key issues revolve around place, space, and time. All places have multiple identities, and they play multiple roles in the flows that link a place with other places. In this context, the multiple roles that a place has developed provide each place with a very distinct place-based or place-bounded identity; this is a two-way relationship between some of these roles and a place's connectivity. In this account, places are in a continual process of becoming. This process reflects the ongoing incremental accumulation of many trillions of decisions that contribute to place-making or place-shaping. All places then have distinct geographies.

There is another way of conceptualizing place that should play a central role in the shift towards a more inclusive social science agenda on place. This is to appreciate that all places are the settings for the development of individual biographies. Thus, a place, at any one point in time, is the outcome of a set of complex interrelationships between place, space, and the biographical narratives of the people who have formerly lived in that place and those who are currently inhabiting that place. These biographical narratives are impacted by place and connections to other places, but they also transform place. An emphasis on understanding the interrelationships between biographies and 
place is one way of developing a more inclusive social science research agenda on place.

There is a danger that a call for research to focus on more ordinary places is seen as a call for the development of some form of place-based typology. Global cities have been ranked multiple times, and thus more ordinary places could also be ranked. Nevertheless, this is not a call for a typology of places, but instead for a greater appreciation of the diversity and complexity of the interrelationships between place, space, and biographical narratives. The key questions include 'how are lives shaped by their engagement with place and space and the role they play in transforming place?' and 'how are organizations shaped by place and space and the role they play in transforming place?'

There are two things to consider. First, is the relationship between the 'universal' and the 'particular'. All places are 'particular' in some ways. For social science, a key challenge is to distinguish between the universal and the particular. The danger is that the 'universal', which is reflected in theory, is perhaps too much a reflection of biographical narratives of people and organizations based in larger places with very different identities and connectivities compared to much more ordinary places. One critique made of geography by academics involved in the quantitative revolution was that geography was not a science as the literature was too focused on the peculiarities of place. Today, perhaps the critique is that geographers need to pay much more attention to understanding the peculiarities of place.

Second, Georges Perec, the French novelist, published a novel in 1987 under the title Life: A User's Manual. This begins with a discussion of jigsaw puzzles and pieces. The relationship between a jigsaw and an individual puzzle piece is similar to that between the 'universal' and the 'particular'. To Perec, a piece is only readable when included within a puzzle, and once fitted into its neighbours, the piece disappears. This is an account of the interrelationship between 'pieces' and 'pattern'. For social science, there has been too much emphasis on understanding some places/pieces and this has led to the development of a less inclusive geography and a distorted understanding of the relationships between people, organizations, place, and space. In 2015, Michael Chisholm, Emeritus Professor of Geography, University of Cambridge, published a detailed account of an ordinary place - Crowland, Lincolnshire. This analysis is positioned around a jigsaw analogy in which writing the history of a place 'is rather like constructing a whole jigsaw when numerous pieces are missing' (Chisholm, 2015: 15). Social science is an exercise in trying to identify and sort pieces to form patterns. There are two dangers here. On the one hand, there might be too much of a focus on trying to understand some 'pieces' and place-based patterns and the outcome is a more exclusionary approach to understanding people, organizations, and place. On the other hand, there is a danger that patterns are identified when there is no pattern. There are 
spatial as well as aspatial processes and there are processes in which there is no apparent pattern. One paradox is that aspatial processes might be as important as spatial processes in understanding the place-making or -shaping process and this will also be the case for processes that are not part of a broader pattern.

This edited collection returns to Jennifer Robinson's call for geographers, and those interested in place, to pay more attention to ordinary cities or those places that have been overlooked or relegated as being of less importance in the geographical literature. All places have distinct differences, but there are perhaps some more universal processes. The danger is that we are not yet sure if universal processes exist, and what these might be. In any case, it might be that place-based distinct differences are more important in shaping biographical narratives and in shaping place. This is to highlight the tensions between the role place plays in shaping biographies and the role that biographies play in shaping place.

John R. Bryson, Ronald V. Kalafsky and Vida Vanchan January 2021

\section{REFERENCES}

Chisholm, M. (2015), In the Shadow of the Abbey: Crowland, Fast-Print Publishing: Peterborough.

Perec, G. (1987), Life: A User's Manual, Vintage: London. 